\title{
Hermeneutic Phenomenology: Essence in Educational Research
}

\author{
Megh R. Dangal \\ Kathmandu University, NEPAL \\ School of Arts, Department of Development Studies \\ Rupendra Joshi \\ Tribhuvan University, Lalitpur, NEPAL \\ Faculty of Management
}

Received: 16 June 2020 - Accepted: 1 October 2020 • Published Online: 26 October 2020

\begin{abstract}
This article shows how and why hermeneutic phenomenological research can promote knowledge and understanding in research practices in education. The main focus of the article is aimed to provide rich textual descriptions of the experiencing of selected phenomena in the life world of individuals that are able to connect with the experience of all. It gives a brief overview of hermeneutic phenomenology and discuss its use in research work in education. The paper also presents on the diverse field of application, recent developments and the essence of hermeneutic phenomenological in education research. The article further examines the philosophical standpoint and establishes its linkages with various other methodologies. Finally, paper concludes with Clark Moustakas phenomenological data analysis for the analysis of the gathered data consisting three main components: phenomenological reduction, imaginative variation, and synthesis to come to the conclusion. This article demonstrates and explores the value of hermeneutics as a credible, rigorous, and creative way to address the different aspects of professional practices and how hermeneutic phenomenology is useful in studying the personal and social facets of making psychological knowledge and searching for philosophical truth as a research methods in educational research.
\end{abstract}

Keywords: phenomenology, hermeneutic phenomenology, phenomenon, essence, lived experience, educational research.

\section{Introduction: Hermeneutic phenomenology}

Hermeneutics is the theory and practice of interpretation (van Manen, 2014). It is a method of textural analysis with an artful form of understanding and a process of exposing hidden meanings (van Manen, 2006). Hermeneutics was derived from the Greek verb, hermeneueuein, to "interpret", and from the noun, hermeneia, or "interpretation" (Thompson, 1990). Therefore, it is associated with the interpretation of the text.

Hermeneutic phenomenology aims to elucidate lived meanings. It means it attempts to describe and interpret lived experiences meanings to a certain degree of depth and richness (van Manen, 1990). Hermeneutics focuses on subjective experience of individuals and groups and

(C) Authors. Terms and conditions of Creative Commons Attribution 4.0 International (CC BY 4.0) apply. Correspondence: Megh R. Dangal, Kathmandu University, School of Arts, Department of Development Studies, Kathmandu, NEPAL. E-mail: megh@ku.edu.np. 
is an attempt to unveil the world as experienced by the subject through their life world stories and this type of research is conducted through empirical (collection of experiences) and reflective (analysis of their meanings) activities (van Manen, 1990). Crowther, Ironside, Spence and Smythe (2016) state that hermeneutic phenomenology is a methodological approach not bounded by structured stages of a method, instead it is related to how one attunes, questions, and thinks in a circular manner. According to Patton (2002), hermeneutic phenomenology focuses on exploring on how human beings experience the phenomenon i.e., how human being perceive it, describe it, make sense of it to reach understanding. In hermeneutic phenomenology, the researcher does not only describe the phenomena but jointly interprets the whole process of understanding of phenomena along with the participants. As a result, the validity of the interpretation is (Creswell, 2009).

Hermeneutic phenomenologist requires interpretation to bring out the ways in which the meaning occurs in a context. The lived experience of the participants needs to be seen in the context of that individual's life situation. It is an interpretive research that advocates the natural setting of qualitative research and seeks a deeper understanding of what it means to be human (Gearing, 2004). It is the study of everyday, lived experiences and the meanings we construct from them (van Manen, 1990). It is based on two main assumptions of phenomenological research i.e., human seeks meaning in their lives, and there are multiple realities in socially constructed meaning.

According to Christensen, Johnson and Turner (2010) the primary objective of phenomenological research is to explicate the meaning, structure, and essence of the live experiences of a person, or a group of people, around a specific phenomenon. This research approach allows the researchers to reveal the "essence of things" and provides insights into social phenomenon (Creswell, 2015). Phenomena are the building blocks of human science and the basis for all knowledge (Moustakas, 1994). Phenomenology includes transcendental, existential, and hermeneutics, among others (Audi, 2001). There are different approaches to phenomenology. Embree (1997) identified seven approaches namely: descriptive (transcendental) phenomenology, naturalistic phenomenology, existential phenomenology, generative historicist phenomenology, genetic phenomenology, hermeneutic (interpretive) phenomenology, and realistic phenomenology.

Amongst these phenomenological approaches, transcendental and interpretive phenomenology are the two main approaches that are used to get the insightful information and in-depth understanding of the lived experiences of the participants for research purposes. The present study is confined only to hermeneutic (interpretive) phenomenology (Singleton, 2015).

A phenomenon can be an emotion, relationship, or an entity, a program, an organization, or a culture (Patton, 2002). It is believed that hermeneutics without phenomenology is interpretation without context, without situating in it and phenomenology without hermeneutics is arguably nothing but a façade (Moustakas, 1994).

Hermeneutic phenomenology is heading towards bridging the gap that lies between what theory and educational research documents. It tries to fill up the gap between theory and documents. It tries to fill up the gap between theory and documents that should take place in the classroom and what actually takes place in everyday pedagogical practice (Friensen, 2012). Hermeneutic phenomenology gives the teacher a different knowledge and deeper understanding of what actually goes on in classrooms (Friensen, 2012). It is a seamless way of seeing pedagogy. It rests on three basic components; head (thinking), heart (feeling), and hand (acting) (Singleton, 2015). The general purpose of the phenomenological study is to understand and describe a specific phenomenon in depth and reach at the essence of participants' lived experience of the phenomenon. But the main purposes are:

(1) to seek reality from individuals' narratives of their experiences and feelings, and 
(2) to produce in-depth description of the phenomenon.

Hermeneutic phenomenology puts great emphasis on the knowledge construction and reconstruction process based on the participants experiences and enables the researcher to explore more authentic perspective of the participants (Langdridge, 2007).

\subsection{Hermeneutics and interpretation}

Hermeneutics need interpretation and interpretation refers to the meanings derived from the analysis of the collected data, information, and evidences. Patton (2002) defines interpretation as: "attaching significance to what was found, making sense of findings, offering explanations, drawing conclusions, extrapolating lessons, making inferences, considering meanings, and otherwise imposing order on an unruly but patterned world (p. 480).”

As a hermeneutic phenomenological study, the interpretive meanings are as significant as the experiential descriptions of the lived experiences (Risser, 1997) and allows interpretation through the lenses of researchers and make the meanings in a way that is credible and faithful to the participants and their interpretations. Besides, the interpretation is implicated to make sense of data by drawing on the researchers' subjective understanding and life experiences (Finlay, 2003). According to Heidegger (1982) hermeneutics can be defined as a way to "interpret the shared meanings and practices that we have for our experiences within a context" (Maloney, 1993: 40) of the participants as lived experiences of the participants is the main insightful source of information. Hermeneutics pertains to the process of exposing hidden meanings (Allen, 1995). In hermeneutic phenomenology, the researchers interpret human experiences as a text that offers rich and deep accounts of phenomena (Hein \& Austin, 2001). The interpretive process continues until a moment in time where one reaches to sensible meanings of the experience, free from inner contradictions (Kvale, 1996).

\subsection{Hermeneutic circle}

In hermeneutics, hermeneutic circle explores the understanding of the context of the participants. So, it refers to the interpretive process that moves from components of experience to the whole experience and back again and is continued to deepen the depth of understanding and engagement with texts (Ajjawi \& Higgs, 2007). Hermeneutic circle describes how the part and whole are related and interrelated with each other in understanding and interpreting the process. Without understanding the component, the whole is incomplete. The component and whole gives the complete meaning and therefore is circular (Gadamer, 1975). It shows the dialectical relationship between the part and the whole. For example: the word or sentence spoken by the person is the context that reveals his/her socio-culture, tradition, history and so on and shows the dialectical relationship between the context of the words spoken and the context of the socioculture context. The hermeneutic circle of interpretation is an ongoing process with movement from whole to the part and back to the whole (Ajjawi \& Higgs, 2007). Therefore, it is a circle of understanding.

Stephenson, Giles and Bissaker (2018) writes that engaging with research texts in a different ways, and coming back to the same piece of text over and over again in order to have further meanings and understandings is a hermeneutic circle. With the help of this hermeneutic circle, the researcher goes back and forth, closer and further, away and towards the ontological nature of the subject matter (Stephenson et al., 2018). Therefore, hermeneutic circling brings researchers own experiences back to life in vivid ways along with deeper exploration of the understandings they've garnered in their earlier experiences. 


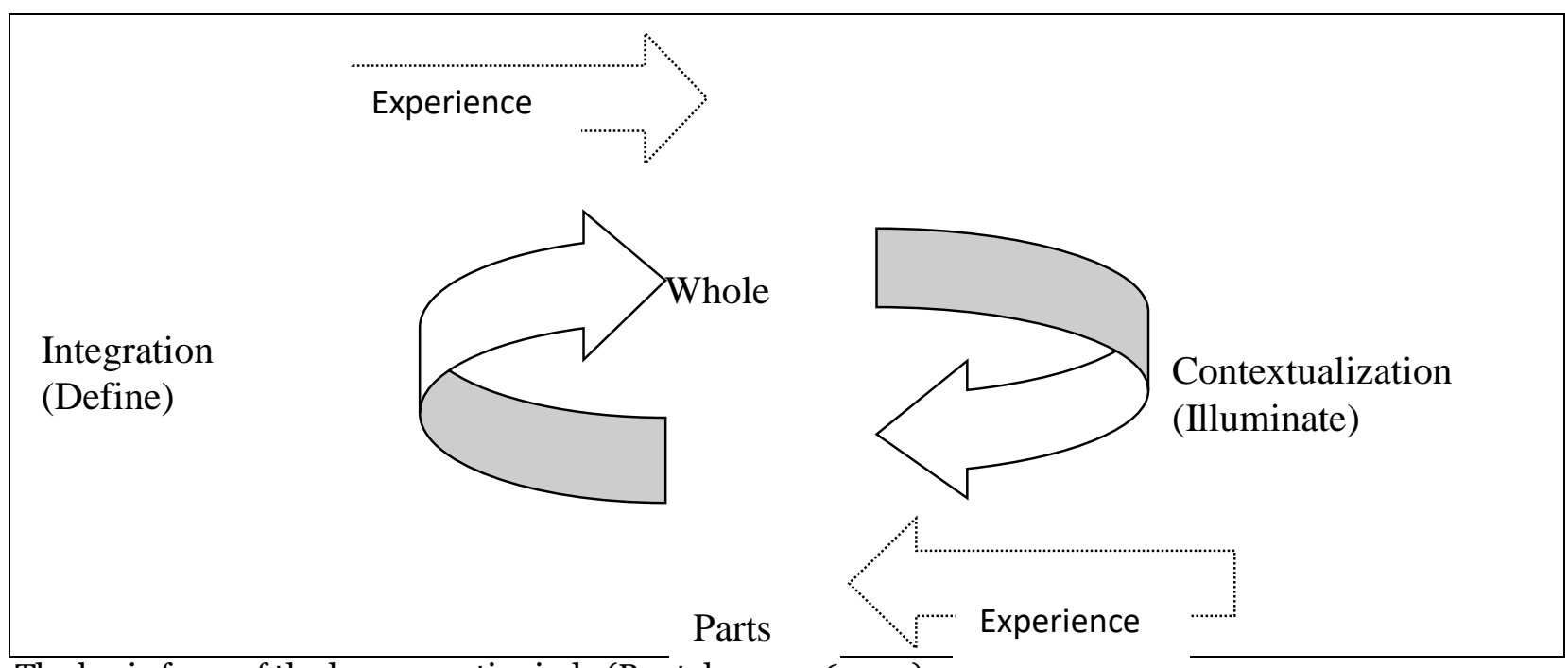

The basic form of the hermeneutic circle (Bontekoe, 1996, p. 4).

Figure 1. Hermeneutic circle

As per Heidegger, hermeneutic circle is the process that explains "how what is understood forms the basis for grasping that which still remains to be understood" (Bontekoe, 1996: 2). In the hermeneutic circle, we not only make progress towards sense and meaning by questioning prior knowledge but also expand it into new horizons of meanings (Mullay, 1997). Thus, the hermeneutic circle is a metaphor for understanding and interpretation, which is viewed as a movement between parts (data) and whole (evolving understanding of the phenomenon), each giving meaning to the other such that understanding is circular and iterative (see Figure 1). In this context, the text is a creation of the researcher from the collected data of the participants. The dialogue between the researcher and the text give the understanding of the text as a whole of the research (Bontekoe, 1996) giving the hermeneutic research goal to fuse the horizons of past, present, and future understanding using the hermeneutic circle (van Manen, 2014)

The idea of the hermeneutic circle is much more complex and multi-layered than what is currently reflected. Hermeneutics can be applied in knowing and understanding meaning embedded in different subjects (Carpenter, 2007). The in-depth studies of hermeneutics in IS (Information System) help to solve the previously divided philosophy of positivism and interpretivism (Kroeze \& Zyl, 2018).

Hermeneutic circle is popular in IS research and practice. Hansen and Rennecker (2010) refer hermeneutics to the basic meaning of movement between partial and holistic understanding concept. This concept can be used as a model and extended to facilitate the process of understanding and consensus in groups. Therefore, Hansen and Rennecker (2010) refer the hermeneutic circle as the lifecycle of information systems. Ying et al. (2006) refer to the hermeneutic circle to show how holistic understanding follows from an iterative interpretive process between the parts and the whole, or the individual and the group. According to Myers (2004), hermeneutics can be used to interpret texts and text analogues (such as organizational culture), to enhance systems development and to evaluate how systems are accepted and how they affect organizations and society after implementation. Hermeneutics enriches IS (Information System) philosophy, theory, research and practice (Kroeze \& Zyl, 2018). As per Hansen and Rennecker (2010), when groups or teams have to understand the given (same) text and have to agree on the meaning of the text (as in systems analysis and design projects), hermeneutic principles could be helpful to facilitate an iterative process of insight, communication and finding consensus. 


\subsection{Philosophical standpoint}

From the lens of Philosophy, hermeneutics has been theorized and applied as a philosophical framework and interpretive research methodology paying attention to linguistic, social, cultural, science, technology, information system and historical contexts to understand the life world and human experiences (Charlene et al., 2017). Hermeneutic Phenomenology as a qualitative research methodology is concerned with the phenomenon of human consciousness (Moustakas, 1994). This methodology allows the researchers to reveal the "essence of things" and provides insights into social phenomenon. This methodology is being used in psychology, education, nursing, and other research. The main purpose of the phenomenological approach is to illuminate and identify the phenomena through how they are perceived by the actors in a particular situation. This methodology is particularly effective in bringing the experiences and perceptions of individuals from their own perspectives in order to understand the text of the context.

Philosophy is concerned with different views about how the world works. It focuses on reality, knowledge and existence (van Manen, 2014). Each and every one individual view of the world is closely linked to what one perceives as reality. The perceive reality and the world around may be different. This individual perception of reality affects gaining of knowledge of the world and the act within it. The hermeneutic phenomenology tells about the individual perceptions about understanding and belief of a particular situation and culture. This gives researcher to open up the hidden meanings that the people are holding in their back up and making interpretation (van Manen, 2006).

According to Christensen, Johnson and Turner (2010), the primary objective of phenomenological study is to explicate the meaning, structure, and essence of the lived experiences of the person, or a group of people around a specific phenomenon. In broad sense, the purpose of phenomenology is to describe particular phenomena, or the appearance of things, as lived experience (Speziale \& Carpenter, 2007).

Hermeneutic phenomenology is an approach of knowledge production and strong inclination towards social inquiry methods. Hermeneutic phenomenology is characterized by features of social science research and differs from natural sciences (Kinsella, 2006). Qualitative research and hermeneutic Phenomenology run parallel to each other as both give emphasis on understanding and interpretation as opposed to explanation and verification (Kinsella, 2006). Gadamer (2006) demonstrates that understanding is the fundamental for interpretation of any kind and thus qualitative research and hermeneutics are inter-connected. Hermeneutic approach holds that social life is 'meaning' of an action and therefore social science research must interpret the meaning of social action (Carpenter, 2007). Further, hermeneutics phenomenology rejects the notion of explaining human behavior through positivist approaches.

When we observe hermeneutics from the ontological lens, we observe that reality is perceived as an individual construct dependent to different situations (Crotty, 1988). The reality can be external to individuals or produced by individual consciousness (Cohen \& Morrison, 2000). It refers to our assumptions about how we see the world. It is the theory or study of being as such. Ontology is an explicit specification of conceptualization (Rockmore, 2011). It is the branch of metaphysics (philosophy concerning the overall nature of what things are) concerned with identifying, in the most general terms, the kinds of things that actually exist. The hermeneutic sees the text of the individual from his/her own perception being as such and understand and interpret the embedded meanings within them.

From the epistemological perspective hermeneutics is precisely concerned with providing the kind of philosophical grounding for deciding the kinds of possible knowledge that can ensure the adequacy and legitimacy (Rockmore, 2011) as epistemology is related to the study of nature, origin, and limits of human knowledge. Crotty (1998) asserted that "epistemology is a 
way of understanding and explaining how we know what we know". It refers to the knowledge and the notion that the research work is supposed to make contribution to knowledge itself. Thus, hermeneutic phenomenology is rested on the ground of subjective knowledge (Hartley, 2006). Philosophically hermeneutic phenomenology helps the researchers to bring the historical context, cultural traditions, and people prior knowledge into the hermeneutic circle because such prior knowledge served as an enabler to understand the text (Jacobs, 2014). This philosophical stand point reflect and influence on how one thinks about and seeing the world that help to act in inquiry and practice within the ontological and epistemological orientation (Miles \& Huberman, 1994).

\section{Diverse field of application and recent development}

Hermeneutic Phenomenology is used as a research method in education and other related field such as, healthcare, social work and so on. Hermeneutic takes the concrete minutiae of pedagogy and classroom interaction (Johnson \& Christensen, 2007). It acknowledges the ethical knowledge possessed by the teachers (Toders, 2007).

It has close connection with other theories like feminist, grounded, case study and narrative research. Phenomenology provides deeper understanding of experiences of certain phenomena of different persons in different context. Being able to understand some common phenomenon by the researcher would be very useful to the therapists, psychologists, psychiatrists, policy-makers, teachers, and health personnel (Toders, 2007).

Phenomenology can be used in all the sectors where human instincts, desires, perceptions, feelings, emotions, understandings play a vital role. May it be to access the consumer behavior to assess their choice in economics; to find out the social trend of crime; to assess the cultural transmission phenomena in sociology; may it be to assess the students behavior on learning in Education; can be used to know the felt need of change in certain aspect of social problem in development Studies and so on (Creswell, 2009). So, its scope cannot be limited within a certain periphery and moreover depends on the researcher conscience and prudency to use the method. It can be equally applied in diverse field of education like, life-skills, technical and vocational teaching, classroom management, curriculum development and so on.

A researcher is a seeker of meaning in hermeneutic phenomenology. Its purpose is not to provide information, but to enhance the perspectives and provide exact form of understanding that are situational, relational, and enactive (van Manen, 2014). Therefore, hermeneutic has reflexivity that shows how philosophical and methodological perspectives are practiced and presented and makes sense of human experiences. It prepares report with human existence in a linguistic form (Gadamer, 2006). When hermeneutic phenomenology is used as educational research, it takes teacher as a process of information that involves relational sensibilities and ontological understandings (Giles, 2014) and one can learn from teacher's everyday experiences of 'being-in' their practice. Stephenson, Giles and Bissaker (2018) explain that teaching should be thought of as a phenomenon of inquiry that can be hermeneutically explored through gathering of information, telling and interpretive activities that show the essence and ontological nature of becoming a teacher.

Hermeneutics Phenomenology allows researcher to gain deeper knowledge and understanding to new perspectives on human experiences through interpreting text highlighting the cultural, historical, philosophical, and linguistic characteristics of the research (Charlene et al., 2017). Therefore, researchers can apply the hermeneutics in the diverse fields such as education, clinical psychology, criminology, legal studies, family sciences, nursing, and medicine.

Recent developments in the field of hermeneutic phenomenology are very difficult to locate because of its huge applicability to different research problem and scenario. From the above discussion also, it is now clear that the hermeneutics is applicable in almost all aspects of 
qualitative research (Edie, 1987). It can be equally applied from education to nursing, social science and others. The applicability of hermeneutic phenomenology has also been extended to the quantitative research as well. Therefore, the recent development of hermeneutic phenomenology has been in the field of mixed research. Moreover, to be precise, hermeneutics is now being extensively applied in nursing, information system research, anthropology, etc (Creswell, 2015).

According to Babich (2014), hermeneutics has multidimensionality. The multidimensionality of hermeneutic phenomenology is not limited to certain subject area, it goes beyond the social science and equally applicable for the philosophy of technology, metaphysics, epistemology including aesthetics, as well as explorations of the history of philosophy, theology, and information system (IS). In the beginning hermeneutics was dealt only with the interpretation of biblical texts, and later has been extended to general understanding (Boell \& Cezec-Kecmanović, 2011). Hermeneutics is not only concerned with understanding the text, it is related with the process of developing understanding of text under certain pretext (Boell \& Cezec-Kecmanović, 2011).

\section{Dimensions of experience and challenges in Hermeneutics Phenomenology}

The experience of human beings consists of two interrelated dimensions: noesis and noema (Muostaksa, 1994). Noesis refers to the act of experience, such as perceiving, feeling, thinking, remembering, or judging, whereas noema refers to the object of action, such as perceived, felt, thought, the remembered, and the judged (Audi, 2001). The combination of these two dimensions of the experience makes up the consciousness of an experience (Noesis + Noema $\rightarrow$ Perception).

The relationship between these two essentials is commonly referred as intentionality. When experience is observed from the phenomenological perspective, all the experience of the mankind is intentional experience (van Manen, 2014). Consciousness is always a consciousness of an object because one cannot conscious without being conscious of something, and the consciousness of an object requires a subject (Muostakas, 1994). When a person uses a computer in the Internet café for the educational purpose, it is the noema of the experience and using computers in the internet café is the noesis of the experience (Cilesiz, 2011). Hence, these two dimensions are so interrelated that one cannot exist without the other. Each and every experience consists of textures and structures that give rise to the essence of the experience. Texture is the different outside appearances and the structure is the account of the texture or the underlying issue of the texture. Therefore, experience is the manifestation of the essence.

One of the important assumptions of Husserlian phenomenology is bracketing in which the researcher declares personal biases, assumptions, and presuppositions and put them aside (Gearing, 2004). The aim of this is to keep what is already known about the description of the phenomenon separately from participants' description. The researchers should avoid any imposition of their assumptions on the data collection process or the structure of the data (Speziale \& Carpenter, 2007). This gives clear understanding and interpretation of the participants' feelings. To study human experience, one needs to go through description of the major concepts and essences along with looking for meanings embedded in common life practices which is a big challenge for hermeneutic phenomenologists.

Gadamer (2006) assert phenomenology means adopting a certain attitude, a particular mode of attention towards the world and the way we conceptualize the meaning of experience. He called this phenomenological reduction, and argued that there is a need to constantly go "back to the things themselves" and the way they are presented to us. An important way of checking the validity of a phenomenological analysis is to compare the analysis against the 
original data, "the things themselves" which in itself is a challenge for researcher (Gadamer, 2006).

\section{Research design and paradigm of hermeneutic phenomenology}

Hermeneutics is the science of interpretation (Crotty, 1998). So, hermeneutics use the Interpretive Research Paradigm (IRP) to conduct the research process. The interpretive research paradigm is based on the epistemology of idealism (in idealism, knowledge is viewed as a social construction) and encompasses a number of research approaches, which have a central goal of seeking to interpret the social world (Hein \& Austin, 2001). The interpretive paradigm reflects recognition that meaning is a human construction. According to the interpretive paradigm, the meaning people attribute to things in the world around them is not only constructed but contingent. This means that the meaning constructed depends heavily on contextual features, that is, on the particular history, place, and culture that people bring to any act of meaning-making (Cilesiz, 2011).

The Interpretive Research Paradigm (IRP) allows or enables the researcher to have indepth knowledge or deeper understanding of the experiences of the participants through the indepth interview. It is reflexive in nature and the reflexivity enables the researcher towards the deeper understanding of the phenomenon being researched. As per the interpretive research paradigm, the meaning people attribute to things in the world around them is not only constructed but contingent (Stiegler, 2010). It means that the meaning constructed depends heavily on contextual features and the culture that people bring to any act of meaning-making. In the words of Hiedegger, to be human means to be constantly interpreting the world around us, and to live within a world made up of interpretations (Hiedegger, 1982). The hermeneutic phenomenology is aimed at producing rich textual descriptions of the experiencing of the participants life world.

The given research design/model clearly describes how hermeneutics phenomenology take place in the given context to interpret the original data of the participants. The knowledge gained from the internal and external world help to have experiences amongst the participants which then through the hermeneutic circle establishes the whole of the text and give rise to the essence of understanding. The data collected through in-depth interview and participants' observation are analyzed by using Moustakas Phenomenological Data Analysis tools to get the inference and interpretation of the findings. Interpretivism is more based on humanistic philosophy than positivism and provides a basis for a wide variety of qualitative research (Gadamer, 2006). Hiedegger believed that the meaning embedded in common life practices is not obscure, it can be extracted from the narratives generated by people and the relationship between an individual and his/her world should be the focus of phenomenological inquiry (Lopez \&Wills, 2004). The use of hermeneutic phenomenology enables the researcher in exploring the participants' experiences with further abstraction and interpretation. It helps in explicating meanings and assumptions in the participants' texts that they have difficulty in articulating by themselves. 


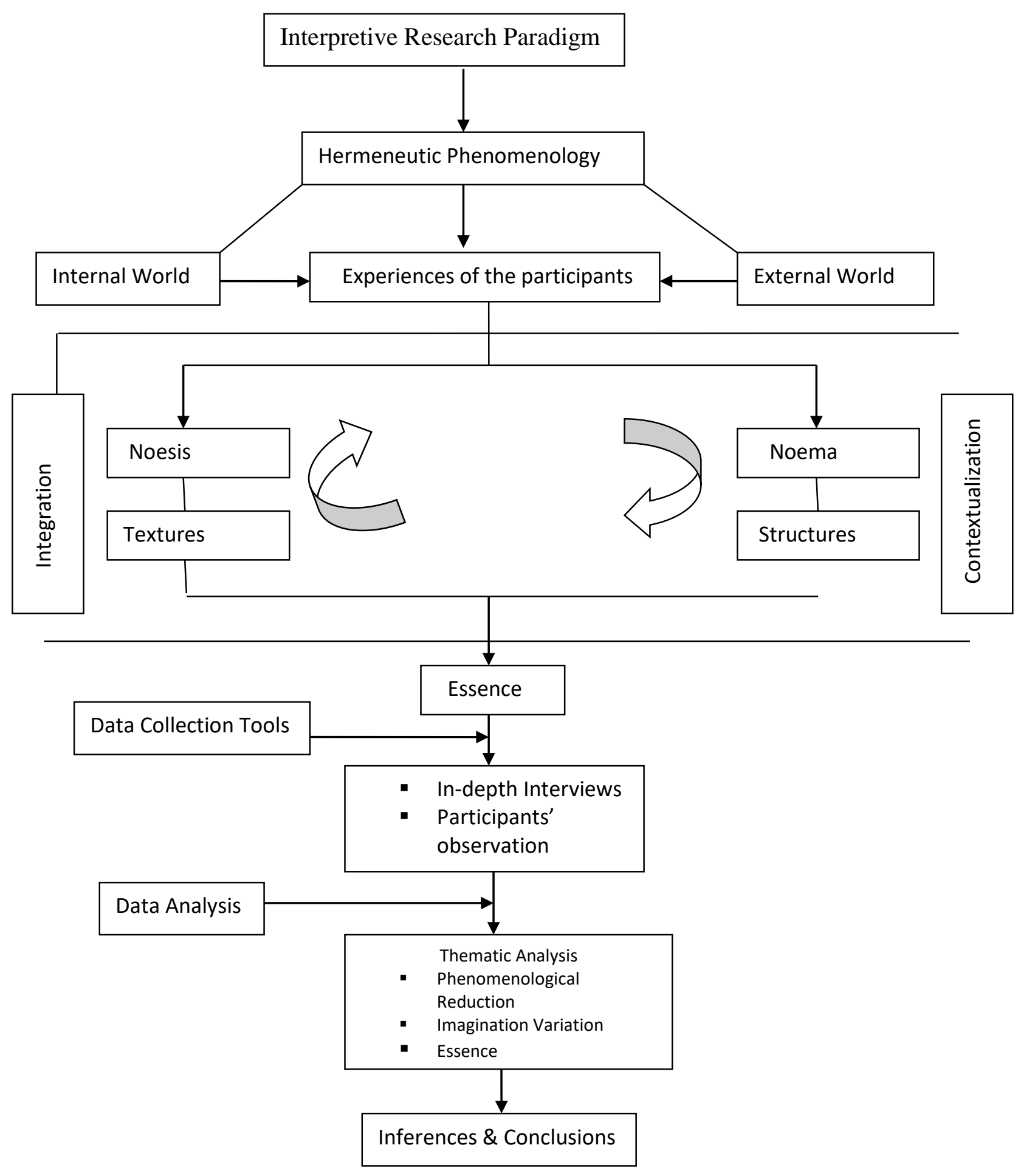

Figure 2. Research design model of hermeneutic phenomenology 


\section{Data collection tools for hermeneutic phenomenology}

Data collection is an essential component in conducting research. It is a hard and tough task. The most common means of data collection in a phenomenological study is through in-depth interviews to gather lived experiences of the participants' detailed and insights of their experiences and participants' observation (Creswell, 2009).

\subsection{In-depth interview}

In-depth interview is a technique designed to give an opportunity to express participants in a way ordinary life rarely affords them. It is one of the most commonly used techniques in qualitative research. In hermeneutic phenomenology, interview (in-depth) serves very specific purposes (van Manen, 1990). According to Patton (2002), the researcher should conduct in-depth interview with the people who live with or have directly experienced the phenomenon in order to explore the experience of phenomenon. During in-depth interview, the person being interviewed is considered the expert and the interviewer is considered the student. It is usually conducted face-to-face and involve one interviewer and one participant (Denzin \& Lincoln, 2011). The face-to-face nature of the interview allows for immediate clarification or expansion of the participants' thoughts and access to non-verbal cues such as gestures and facial expressions (Speziale \& Carpenter, 2007).

In-depth interviews are useful for learning about the perspective of individuals. It helps to understand about the personal feelings, opinions, and experiences (Frechtling et al., 1997). It gives an opportunity for researcher to gain insight into how people interpret and order world. This interview is especially appropriate for addressing sensitive topics that people might be reluctant to discuss in a group.

\subsection{Participants'observation}

Observation is the direct way of collecting and gathering information by observing events as they occur. Observation is used to access the phenomenon for communicating between the researcher and the participants in the context to observe interactions and possible influencing factors (Creswell, 2009). It helps to verbalize the participants reasoning, reflect upon it, and explain the rationale for it. It is the process of recognizing and noting people, objects, and occurrences rather than asking for information (Creswell, 2015). Observations are used in hermeneutics to have prompt reflections from the participants on their current and past learning journey's and experiences, and to provide points of references for interpretation of findings (Allen, 1995). Besides, by conducting observations the researcher become able to back up his/her interview data and its accuracy with his/her own experience.

This tool helps to generate the data in the real form because the researcher eyes are the only instruments to capture information of the objects in the study (Kavle, 1996). Creswell (1994) viewed that in observation the researcher is actively involved in the reality of the participants' responses. Participant-observation allows the researcher to be physically present in the events being studied.

\section{Phenomenological data analysis}

Phenomenological data analysis starts with bracketing-off the researcher's subjectivity which refers to setting aside the researcher's prejudgments and predisposition towards the phenomenon (Moustaksa, 1994) i.e., researchers keep their subjectivity in reserve throughout the 
study which Moustakas named this act as “epoche process or bracketing”. Moustakas phenomenological data analysis includes:

(a) Phenomenological reduction,

(b) Imaginative variation, and

(c) Synthesis.

The above procedure includes the following steps:

(1) Horizonalize the data (Listing all relevant expressions),

(2)Transforming the data into statements,

(3) Creation of individual textural description,

(4)Elaborating on the individual textural description,

(5) Identifying similarities in the textures of participants.

In horizonalization, transcripts are read for multiple times with a fresh look, and every statement related to the phenomenon are treated with equal value by recording the relevant statements and eliminating those that are not directly related to it.

In reduction of experience, horizons, the filtrate data, are clustered into themes so that each of the theme has only one meaning. This step is followed by thematizing the invariant constituents called as the core themes of the experience.

The themes derived from the participants' experiences are then compared to other methods like: observations, field notes, interview, and literature to verify accuracy. In crafting of individual texture, participants' experiences are described and explained using verbatim in a narrative format to facilitate the participants' experiences (Denzin \& Lincoln, 2000). Similarly, in construction of individual structural description, imaginative variation is used where researcher imagines how the experience occurred and creates the structure. This imaginative variation is followed by construction of composite structural description where structures are added at the end of each paragraph to create structural description. And at the last of the analysis, texture and the structure are synthesize by writing composite narratives by creating meaning units common to all participants to reach to the essence of the experience of the phenomenon.

\section{Quality considerations}

Patton (2002) states that validity and reliability are two important factors to be considered by qualitative researcher in order to maintain the quality of the qualitative research. Healy and Perry (2000) assert that reliability and validity are essential criterion for quality in qualitative research. Reliability and validity are commonly used for testing or evaluating in quantitative research (Golafshani, 2003). Speziale and Carpenter (2007) describe that trustworthiness establishes the validity and reliability in qualitative research.

Lewis and Ritchie (2014) point out that quality of the data and its interpretation are important in maintaining the reliability of findings of a research.

Qualitative research is trustworthy when it accurately represents the experiences of the study participants. The researcher uses Lincoln and Guba (1985) model that identifies credibility, applicability or transferability, consistency or dependability and neutrality or confirmability as essential criterion for establishing trustworthiness and quality in qualitative research:

(i) Credibility,

(ii) Applicability or Transferability,

(iii) Consistency or Dependability,

(iv) Neutrality or Confirmability. 


\subsection{Credibility}

Credibility refers to establishing that the results of qualitative research are believable from the perspective of the participants as the participants are the only ones who can legitimately judge the credibility of the result. Credibility is concerned with the aspect of truth-value. It is equivalent to internal validity in quantitative research (Korstjens \& Moser, 2018). It is the truth of how the participants know and experience the phenomenon. Guba and Lincoln (1989) claimed that the credibility of a study is determined when co-researchers or readers are confronted with the experience, they can recognize it. Credibility establishes whether the research findings represent plausible information gather from the participants' original data and is a correct interpretation of the participants' original views (Korstjens \& Moser, 2018). According to Lincoln and Guba (1985), credibility can be established through prolonged engagement, reflexivity, triangulation, peer and participants debriefing and the process of member checking (sending all transcripts of the interviews to the participants for fee back and presenting findings to the participants) to test the findings and interpretations with the participants. Hermeneutics thus follows these mentioned activities and establishes and demonstrates credibility through the participants' behavioral experiences and their original data.

\subsection{Applicability or transferability}

Applicability or transferability refers to the generalizability of the inquiry. It means, the study findings/results of the qualitative research can be generalized or transferred to other contexts or settings in similar situations. It is also called "fittingness" as it determines whether the findings fit in or are transferable to similar situations (Speziale \& Carpenter, 2007). In qualitative research, the researcher facilitates the transferability judgment by a potential user through thick description (Korstjens \& Moser, 2018). Transferability enables the reader to assess whether the findings are transferable or not to their own settings. In qualitative research, the transfer concerns only to case-to-case transfer (Tobin \& Begley, 2004). It is the judgment of the participant to transfer or not the findings/results of the research, not the researcher, because the researcher does not know their specific settings (Korstjens \& Moser, 2018).

Transferability refers to the degree that findings from research can be generalized to other contexts (Miles \& Huberman, 1994). In hermeneutics, applicability relates to how well the research findings describe factors that influenced the acculturation of international occupational therapy graduates who did not participate in the project. Findings of qualitative studies are generally less amenable to generalization as each participant's situation is considered unique. An essential element of hermeneutics is a thorough understanding of context and its influence upon a studied phenomenon. An understanding of the applicability of findings to other situations is therefore facilitated through the use of hermeneutics (Carpenter, 2007).

\subsection{Dependability or consistency}

Dependability is another criterion to measure trustworthiness of the research findings. It is the stability of data over time (Korstjens \& Moser, 2018). It is related to consistency of findings. It means, when the study is repeated in a similar context with the same participants, the findings would be consistent. Since there can be no validity without reliability, thus there can be no credibility without dependability (Speziale \& Carpenter, 2007). Dependability involves participants' evaluation of the findings, interpretation and recommendations of the study received from participants of the study (Korstjens \& Moser, 2018).

An evaluation of consistency determines whether the process of the study was

"consistent, reasonably stable over time and across researchers and methods" (Miles \& Huberman, 
1994: 278). Hermeneutics provides both the science and the tools that are needed for consistent interpretation of findings (Gadamer, 2006). The constructs of the hermeneutic circle, fusion of horizons and dialogue, integrated into the hermeneutic spiral assist the researcher to consistently address the interpretation of a phenomenon. Explicit procedures are also to be developed and use for selecting the participants for each study phase as well as for collecting and analyzing data in order to promote consistency (Paterson \& Higgs, 2005).

\subsection{Neutrality or confirmability}

Neutrality or confirmability refers to the degree to which the results could be confirmed or corroborated by others (Krefting, 1991). Confirmability is concerned with establishing that the data and interpretations of the findings are clearly derived from the data and not from the figments of the researcher's imagination (Korstjens \& Moser, 2018). According to Guba and Lincoln (1989), confirmability is established when credibility, transferability, and dependability are all achieved. An advantage of the hermeneutic process was the accommodation provided for the preexisting knowledge.

Hermeneutics recognizes that the researcher brings prior knowledge and assumptions into the research process (Gadamer, 1975). As a research strategy, hermeneutics moves beyond description to interpret a phenomenon in light of previous knowledge and theories. The perspectives of researcher and the text become interlocked and findings emerge as a shared understanding of reality. Several initiatives are to be undertaken to ensure that a broad viewpoint of acculturation issues emerged from the study and that the perspectives of participants are not unduly influenced (Korstjens \& Moser, 2018). Using field notes assist in identifying potential biases and assumptions that may arise while interpreting the data provided by participants. Field notes are therefore shared with interview participants four to ensure that their information is appropriately interpreted and conveyed. Attention is also given in obtaining data from a wide range of participants (Roulston, 2011).

\subsection{Triangulation of data}

Triangulation of data is another milestone to make the research more qualitative. Quality of the research can be enhanced through triangulation of the data (Patton, 2002). Patton (2002) claims that the validity and credibility of the findings can be ascertained by data triangulation. Triangulation is a powerful technique that facilitates validation of data through cross verification from two or more sources (Honorene, 2016). If triangulation of data (use of two or more methods) reinforces the same conclusion, then validity claims are strengthened. Hermeneutic phenomenology also uses triangulation of data for the validity and credibility of the research findings to strengthen the quality of research. According to Honorene (2016) triangulation makes the research result bias free, valid and generalizable. Denzin (1978) describes four different forms of triangulation:

(1) Data triangulation,

(2) Investigator triangulation,

(3) Theory triangulation,

(4) Methodological triangulation.

In data triangulation two or more than two methods of analyzing data is used including time, space, and persons in a study. The findings of the study can be corroborated and any weaknesses in the data can be compensated for by the strengths of other data, thereby increasing the validity and reliability of the results (Denzin \& Lincoln, 2011). Data triangulation helps to 
reduce the risk of false interpretations. It can also provide a more complete and comprehensive perspective on a given situation and generate new insights into that situation.

Investigator triangulation involves use of more than one investigator (interviewer, observer, researcher or data analyst) in a study. The investigator triangulation helps to confirm findings across investigators and enhances the credibility of the findings (Denzin, 1978). This type of triangulation is more use in interpretation of textural and structural analysis of the data.

In theory triangulation, multiple theories are used to analyze or to interpret data. Use of multiple theories look at a situation/phenomenon from different perspectives through different lenses with different questions in mind (Denzin, 1978).

Similarly, in methodological triangulation different methods are used to gather the data. Use of different methods increases the confidence of the result of the findings (Bryman, 1988). This help to decrease the deficiencies and biases that come from any single method and compensate the weakness of one method by the strengths of another.

\section{Conclusion}

The most important part in hermeneutic phenomenology is the textural and structural analysis of the lived experiences of the participants where what is expressed by the participants and how it is expressed give the essence of the phenomenon. It is important to note and comprehend that all qualitative research has a phenomenological aspect, but the phenomenological approach cannot be applied to all qualitative research. The hermeneutic phenomenology provides the ways to consider the phenomena of human experience to the means of expressing them and the use of bracketing depends on the researcher conscience and understanding that can address the research question of the study. Therefore, the present study shows how we use hermeneutic phenomenology as research method in education in getting the true reality by understanding the lived experiences of the participants.

Hermeneutics articulates a process and direction for progressively integrating multiple sources and layers of experience and knowing. A creative and credible strategy describing through the metaphors of dialogue, fusion of horizons and hermeneutic circle gives in better understanding and interpretation of the text in the given context. The fusions of past horizons of knowledge with the new information gained through dialogue help to understood in relation to the hermeneutic circle and gain the in-depth understanding of the lived experiences of the participants. Thus, it is imperative to use hermeneutic phenomenology in education research to address and validate the contemporary issues and problems prevailing in the society.

\section{Acknowledgements}

This research did not receive any specific grant from funding agencies in the public commercial, or not-for-profit sectors.

The authors declare no competing interests. 


\section{References}

Ajjawi, R., \& Higgs, J. (2007). Using hermeneutic phenomenology to investigate how experiences practitioners learn to communicate clinical reasoning. The Qualitative Report, 12(4), 612-638. http://www.nova.edu/ssss/QR12-4/ajjawi.pdf.

Alibali, M. (2006). Does visual scaffolding facilitate students' learning? Thousand Oaks: Sage Publications.

Allen, D. (1995). Hermeneutics: Philosophical traditions and nursing practice research. Nursing Quarterly, $8(4), 174-182$.

Audi, R. (2001). The Cambridge dictionary of Philosophy (2nd ed.). NewYork: Cambridge University Press.

Babich, B. (2014).The multidimensionality of hermeneutic phenomenology: From philology through science and technology to theology. Contributions to Phenomenology, 70. http://www.springer.com/series/5811

Boell, S. K., \& Cezec-Kecmanović, D. (2011). Are systematic reviews better, less biased and of higher quality? European Conference on Information Systems 2011 (ECIS 2011). Paper 223. http://aisel.aisnet.org/ecis2011/.

Bontekoe, R. (1996). Dimensions of the hermeneutic circle. Atlantic Highlands, NJ: Humanities Press International.

Bryman, A. (1988). Quantity and quality in social research. London: Unwin Hyman.

Carpenter, D. R. (2007). Phenomenology as method. Philadelphia, PA: Lippincott.

Charlene, A., Guo-Brennan, L., \& Weeks, L. (2017). Conducting hermeneutic research in international settings: Philosophical, practical, and ethical considerations. Journal of Applied Hermeneutics. Author(s).

Christensen, L. B., Johnson, R. B., \& Turner, L. A. (Eds.). (2010). Research methods, design, and analysis. Boston, MA: Allyn \& Bacon.

Cilesiz, S. (2011). A phenomenological approach to experiences with technology: current state, promise, and future directions for research. Educational Technology Research and Development, 59(4), 487-510. http://about.jstor.org/terms.

Cohen, L., \& Morrison, K. (2000). Research methods in education ( $5^{\text {th }}$ Ed.). London: Routledge Falmer.

Creswell, J. (1994). Qualitative and quantitative approaches. Thousand Oaks: Sage Publications.

Creswell, J. (2009). Research design ( $3^{\text {rd }}$ Ed.). Thousand Oaks: Sage publication.

Creswell, J. (2009). Research design: Qualitative, quantitative, and mixed methods approaches (3 ${ }^{\text {rd }}$ Ed.). Los Angeles: SAGE Publication Ltd.

Creswell, J. (2015). Educational research (4 ${ }^{\text {th }}$ Ed.). India: Pearson.

Crowther, S., Ironside, P., Spence, D., \& Smythe, L. (2016). Crafting stories in hermeneutic phenomenology research: A methodological device. Qualitative Health Research, 1-10. https://doi.org/10.1177/1049732316656161

Crotty, M. (1998). The foundations of social research: Meaning and perspective in the research process (1st ed.). Sydney: Allen \& Unwin.

Denzin, N. (1978). Sociological methods: A sourcebook. NY: McGrawHill.

Denzin, N. K., \& Lincoln, Y. S. (Eds.). (2000). Handbook of qualitative research ( $2^{\text {nd }}$ Ed.). Thousand Oaks, CA: Sage.

Denzin, N. K., \& Lincoln, Y. S. (2011). The sage handbook of qualitative research (4 ${ }^{\text {th }}$ Ed.). Thousand Oaks: Sage publication. 
M. R. Dangal \& R. Joshi - Hermeneutic Phenomenology: Essence in Educational Research

Edie, J. M. (1987). Edmund Husserl's phenomenology: A critical commentary. Bloomington: Indiana University Press.

Embree, L. (1997). What is phenomenology? Boston, MA: Kluwer Academic.

Finley, L. (2003). Through the looking glass: Inter-subjectivity and hermeneutic reflection. In L. Finlay \& B. Gough (Eds.). Reflexivity: A practical guide for researchers in health and social sciences (pp. 105-119). Oxford. England: Blackwell Science.

Frechthing, F. M., Sugai, G., \& Horner, R. H. (1997). Interpreting results of social handbook of qualitative research. New Delhi: Sage Publications.

Friensen, N. (2012). Hermeneutic phenomenology in education. Boston: Sense Publishers.

Gadamer, H. G. (1975). Truth and method. London: Sheed and Ward.

Gadamer, H. G. (2006). Classical and philosophical hermeneutics. Theory, Culture \& Society, 23(1), 29 -56.

Golafshani, N. (2003). Understanding reliability and validity in qualitative research. The Quality Report, $8(4), 597-606$.

Gearing, R. (2004). Bracketing in research: A typology. Qualitative Health Research, 14(10), 1429-1452.

Giles, D. (2014). Appreciatively building higher educator's relational sensibilities. The Journal of MeaningCentered Education, 2.

Guba, E. G., \& Lincoln, Y. (1989). Fourth generation evaluation. Newbury Park, CA: Sage.

Hansen, S., \& Rennecker, J. (2010). Getting on the same page: Collective hermeneutics in a systems development team. Information and Organization, 2O(1), 44-63.

Hartley, D. (2006). Pulling us apart? Relativism and instrumentalism in contemporary educational research. Educational Review, 58(3), 269-272.

Healy, M., \& Perry, C. (2000). Comprehensive criteria to judge validity and reliability of qualitative research within the realism. Qualitative Market Research, 3(3), 118-126.

Heiddeger, M. (1982). The basic problem of phenomenology. Bloomington, IN: Indiana University Press.

Hein, S. F., \& Austin, W. J. (2001). Empirical and hermeneutic approaches to phenomenological research in psychology: A comparison. Psychological methods, 6, 3-17.

Honorene, J. (2016). Understanding the role of triangulation in research. Scholarly Research Journal for Interdisciplinary Studies, 4(31), 91-95.

Jacobs, A. H. M. (2014). Critical hermeneutics and higher education: A perspective on texts, meaning and institutional culture. South African Journal of Philosophy, 33(3), 297-310. https://doi.org/10.1080/02580136.2014.948327

Johnson, B., \& Christensen, L. (2007). Educational quantitative, qualitative, and mixed research. Boston: Sense Publishers.

Kavle, S. (1996). Interviews. In An introduction to qualitative research interviewing. California: Sage Publications.

Kinsella, E. A. (2006). Hermeneutics and critical hermeneutics: Exploring possibilities within the art of interpretation. Forum Qualitative Sozialforschung / Forum: Qualitative Social Research, 7(3). http://www.qualitativeresearch.net/index.php/fqs/article/view/145/319. Article 19.

Krefting, L. (1991). Rigor in qualitative research: The assessment of trustworthiness. American Journal of Occupational Therapy, 45, 214-222.

Kroeze, J., \& Zyl, I. (2018). The theme of hermeneutics in IS: The need for a structured literature review. http://www.researchgate.net/publication/324571303.

Korstjens, I., \& Moser, A. (2018). Practical guidance to qualitative research. European Journal of General Practice. Taylor \& Francis. 
Langdridge, D. (2007). Phenomenological psychology: Theory, research and method. London: Pearson Education Ltd.

Lewis, J., \& Ritchie, J. (2014). Generalizing from qualitative research. Qualitative research practice: $A$ guide for social science students and researchers. London: Sage Publications.

Lincoln, Y. S., \& Guba, E. G. (1985). Naturalistic inquiry. Beverly Hills, CA: Cage

Lopez, K., \& Wills, D. (2004). Descriptive verses interpretive phenomenology: Their contribution to nursing knowledge. Quality Health Research, 14, 726-735.

Maloney, M. (1993). Silent strength: A Heideggerian hermeneutical analysis of the stories of older women. Unpublished doctoral dissertation, Georgia State University, Atlanta.

Myers, M. D. (2004). Hermeneutics in information systems research. In J. Mingers \& L. Willcocks (Eds.) Social theory and philosophy for information systems (pp. 103-128). West Sussex: Wiley \& Sons.

Miles, M., \& Huberman, A. M. (1994). Qualitative data analysis ( $2^{\text {nd }}$ Ed.). Thousand Oaks, CA: Sage.

Moustakas, C. (1994). Phenomenological research methods. Thousand Oaks, CA: Sage.

Mullaly, B. (1997). Structural social work (2 ${ }^{\text {nd }}$ Ed.). Don Mills, Ontario, Canada: Oxford University Press.

Paterson, M., \& Higgs, J. (2005). Using hermeneutics as a qualitative research approach in professional practices. The qualitative Report, 10(2), 339-357.

http://nsuworkas.nova.edu/tqr/vol10/iss2/9.

Patton, M. Q. (2002). Qualitative evaluation and research methods. Thousand Oaks, CA: Sage.

Risser, J. (1997). Hermeneutics and the voice of the other. New York: State University of New York Press.

Rockmore, T. (2011). Kant and phenomenology. Chicago, IL: University of Chicago Press.

Roulston, K. (2010). Reflective interviewing: A guide to theory and practice. Thousand Oaks, CA: Sage.

Singleton, J. (2015). Head, heart and hands model for transformative learning: Place as context for changing sustainability values. Journal of Sustainability Education, 9. Retrieved from http://www.susted.org/.

Speziale, H., \& Carpenter. D. R. (2007). Qualitative research in nursing: Advancing the humanistic imperative ( $4^{\text {th }}$ Ed.). Philadelphia: Lippincott, Williams and Wilkins.

Stephenson, H., Giles, D., \& Bissaker, K. (2018). The power of hermeneutic phenomenology in restoring the centrality of experiences in work-integrated learning. International Journal of WorkIntegrated Learning, 19(3), 261-271.

Stiegler, B. (2010). Taking care of youth and the generation. Stanford, CA: Stanford University Press.

Thompson, T. (1990). Hermeneutic inquiry. In L.E. Moody (Ed.), Advancing nursing science through research. Newbury park, CA: Sage.

Tobin, G. A., \& Begley, C. M. (2004). Methodological rigour within a qualitative framework. Journal of Advanced Nursing, 48, 388-396. https://doi.org/10.1111/j.1365-2648.2004.03207.x

Toders, L. (2007). Embodied enquiry: Phenomenological touchstones for research, psychotherapy and spirituality. Basingstoke, Hampshire: Palgrave Macmillan.

van Manen, M. (1990) Researching live experience. Albany, NY: State University of New York Press.

van Manen, M. (2006). Researching lived experience. Ontario: The Althouse Press.

van Manen, M. (2014). Phenomenology of practice: Meaning-giving methods in phenomenological research and writing. Walnut Creek, CA: Left Coast Press.

Ying, T., Wang, E., Jiang, J., \& Klein, G. (2006). Knowledge integration in ERP project success: A hermeneutic focus. International Research Workshop on IT Project Management 2006. http://aisel.aisnet.org/irwitpm2006/5. 
M. R. Dangal \& R. Joshi - Hermeneutic Phenomenology: Essence in Educational Research

C O A $\mathrm{s}$ 